FRANCO, J.F.L. et al. Lesões post-mortem de equinos abatidos em frigorífico exportador de Araguari - MG. PUBVET, Londrina, V. 5, N. 34, Ed. 181, Art. 1223, 2011.

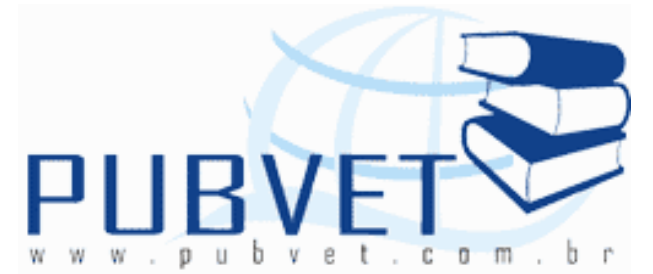

PUBVET, Publicações em Medicina Veterinária e Zootecnia.

\title{
Lesões post-mortem de equinos abatidos em frigorífico exportador de Araguari - MG
}

Jacqueline Fernandes Lima Franco ${ }^{1 *}$, Raquel Peres de Oliveira ${ }^{2}$, Silvia Ferreira dos Santos ${ }^{2}$, Mariana Assunção de Souza ${ }^{2}$

${ }^{1}$ Médica Veterinária

${ }^{2}$ Mestranda em Ciências Veterinárias pela Faculdade de Medicina Veterinária, Universidade Federal de Uberlândia. Uberlândia, MG.

*Autor para correspondência: Rua Ceará, s/n, Bloco 2D, sala 43, CEP 38405303, Uberlândia, MG, Brasil. E-mail: raquelperes_o@yahoo.com.br

\section{Resumo}

Este trabalho teve como objetivo verificar e analisar as principais ocorrências post - mortem em eqüinos, asininos e muares abatidos em matadouro frigorífico exportador de Araguari - MG no período de 2004 a 2008. A pesquisa foi desenvolvida em Matadouro frigorífico exportador de Araguari através da análise dos arquivos contendo dados das patologias encontradas nos eqüinos abatidos. As patologias de maior ocorrência foram: brucelose, linfadenite, lesão supurada, lesão traumática e neoplasia. Para análise dos dados utilizouse estatística descritiva. A maior prevalência encontrada foi para lesão traumática com 1,886\%, a linfadenite ocupou o segundo lugar com 1,193\%, as outras patologias analisadas tiveram os seguintes valores: $0,896 \%$ para neoplasia, 0,540\% para lesão supurada e 0,164\% para brucelose.

Palavras-chave: Eqüídeos, Inspeção post - mortem, Patologias, Carne equina 
FRANCO, J.F.L. et al. Lesões post-mortem de equinos abatidos em frigorífico exportador de Araguari - MG. PUBVET, Londrina, V. 5, N. 34, Ed. 181, Art. 1223, 2011.

\title{
Post-mortem lesions of horses in slaughterhouse export of Araguari, MG
}

\begin{abstract}
This study aimed to verify and analyze the major events post - mortem in horses, donkeys and mules butchered in slaughterhouse in Araguari - MG from 2004 to 2008.The study was conducted in slaughterhouse exporting Araguari SIF 1803 through analysis of data files containing the diseases found in horses killed. The most frequent pathologies were: brucellosis, lymphadenitis, suppurative lesions, traumatic injury and neoplasia. Data analysis used descriptive statistics. The highest prevalence was found to traumatic injury with $1.886 \%$ lymphadenitis ranked second with $1.193 \%$, the other conditions examined had the following values: $0.896 \%$ to neoplasia, $0.540 \%$ to suppurative lesions and $0.164 \%$ for brucellosis.
\end{abstract}

Keywords: Horses, Inspection post - mortem, Pathologies, Horse meat

\section{Introdução}

A produção de carne eqüina no Brasil destina-se ao mercado externo, sendo o valor do mercado interno praticamente inexistente, embora existam estabelecimentos que possam comercializar a carne internamente e legalmente. Existem algumas patologias e também alterações de origem não infecciosa que podem comprometer a exportação da carne eqüina (RODRIGUES et al., 2004).

Algumas alterações podem reduzir os números das exportações de carne eqüina no Brasil como por exemplo a brucelose, linfadenite, neoplasias, lesões supuradas e lesões traumáticas.

A brucelose nos eqüinos é uma doença infecciosa de evolução crônica, de potencial zoonótico. Brucella abortus, Brucella suis e Brucella melitensis podem infectar os eqüinos, sendo que em nosso meio a Brucella abortus é a principal fonte de contaminação, devido ao estreito contato dos eqüinos com o gado (ACHA; SZYFRES, 2003). A brucelose nos eqüídeos manifesta-se sob a 
FRANCO, J.F.L. et al. Lesões post-mortem de equinos abatidos em frigorífico exportador de Araguari - MG. PUBVET, Londrina, V. 5, N. 34, Ed. 181, Art. 1223, 2011.

forma de lesões articulares crônicas e, raramente por abortamentos. As lesões mais sugestivas da doença são: inflamações em ligamentos, como bursites cervicais, nucais e interescapulares, popularmente denominadas "mal da cernelha", "mal da cruz", "mal da nuca" ou "abscesso de cernelha" (Vasconcellos et al., 1987).

A linfadenite é, por definição, qualquer inflamação que ocorra nos nódulos linfáticos. Os agentes infecciosos ou seus produtos são as causas mais comuns de linfadenite. A maioria dos casos dessa doença é de causas inespecíficas. É observada em nódulos que drenam a enfermidade inflamatória primária de outros órgãos ou tecidos, essa reação também pode ser denominada de reação de drenagem por linfonodos (JONES et al., 2000).

A lesão supurada é caracterizada pela formação de grandes quantidades de pus, um exsudato purulento líquido de cor e consistência cremosas. A principal característica do pus é a presença de muitos granulócitos polimorfonucleados neutrófílicos, que juntamente às células preexistentes do tecido necrosados constituem o pus (JONES et al. 2000).

Se referindo as lesões traumáticas, o transporte rodoviário em condições desfavoráveis, é o principal causador destas lesões, e também podem levar a perda de peso, estresse e até provocar a morte dos animais (ROÇA, 2002).

Entre as neoplasias que acometem os equinos destacam-se os melanomas, que dentre os animais domésticos são os mais afetados, principalmente os animais com idade avançada, de pelagem branca ou tordilha e acima de seis anos de idade. As lesões tumorais são geralmente localizadas na derme, e podem disseminar metástases provocando disfunções em órgãos, causando até a morte (BONESI, et al., 1998).

Este trabalho teve como objetivo analisar as cinco principais ocorrências registradas na inspeção post - mortem em eqüinos abatidos em matadouro frigorífico de Araguari no período de 2004 a 2008. 
FRANCO, J.F.L. et al. Lesões post-mortem de equinos abatidos em frigorífico exportador de Araguari - MG. PUBVET, Londrina, V. 5, N. 34, Ed. 181, Art. 1223, 2011.

\section{Material e métodos}

A pesquisa foi desenvolvida em Matadouro frigorífico exportador de Araguari por meio da análise dos arquivos contendo dados das patologias encontradas nos eqüinos abatidos durante os anos de 2004 a 2008. Foram utilizadas fichas relativas ao movimento diário de abate e patologias encontradas no exame pós-motem em eqüinos, asininos e muares.

Utilizou-se como critério de contagem que cada um quarto da carcaça registrada no livro equivale a uma ocorrência. Para análise, utilizou-se a estatística descritiva.

\section{Resultados e Discussão}

As principais ocorrências de eqüinos verificadas foram: lesão traumática, linfadenite, neoplasia, lesão supurada e brucelose.

O total de animais abatidos e o total de ocorrências post-mortem diagnosticadas em eqüinos são apresentados na Tabela 1.

Tabela 1. Número de casos das principais ocorrências post-mortem diagnosticadas no frigorífico exportador de Araguari - MG, no período de 2004 a 2008.

\begin{tabular}{ccccccc}
\hline Ocorrências & $\mathbf{2 0 0 4}$ & $\mathbf{2 0 0 5}$ & $\mathbf{2 0 0 6}$ & $\mathbf{2 0 0 7}$ & $\mathbf{2 0 0 8}$ & Total \\
\hline Brucelose & 48 & 61 & 48 & 34 & 35 & 226 \\
Linfadenite & 372 & 596 & 347 & 239 & 90 & 1644 \\
Neoplasia & 314 & 244 & 303 & 228 & 146 & 1235 \\
Lesão Traumática & 567 & 844 & 522 & 343 & 323 & 2599 \\
$\begin{array}{c}\text { Lesão Supurada } \\
\text { TOTAL DE }\end{array}$ & 118 & 186 & 156 & 165 & 119 & 744 \\
OCORRÊNCIAS & 1419 & 1931 & 1376 & 1009 & 713 & 6448 \\
$\begin{array}{c}\text { TOTAL DE ANIMAIS } \\
\text { ABATIDOS }\end{array}$ & 38359 & 42347 & 24810 & 18565 & 13688 & 137769 \\
& & & & & & \\
\hline
\end{tabular}


FRANCO, J.F.L. et al. Lesões post-mortem de equinos abatidos em frigorífico exportador de Araguari - MG. PUBVET, Londrina, V. 5, N. 34, Ed. 181, Art. 1223, 2011.

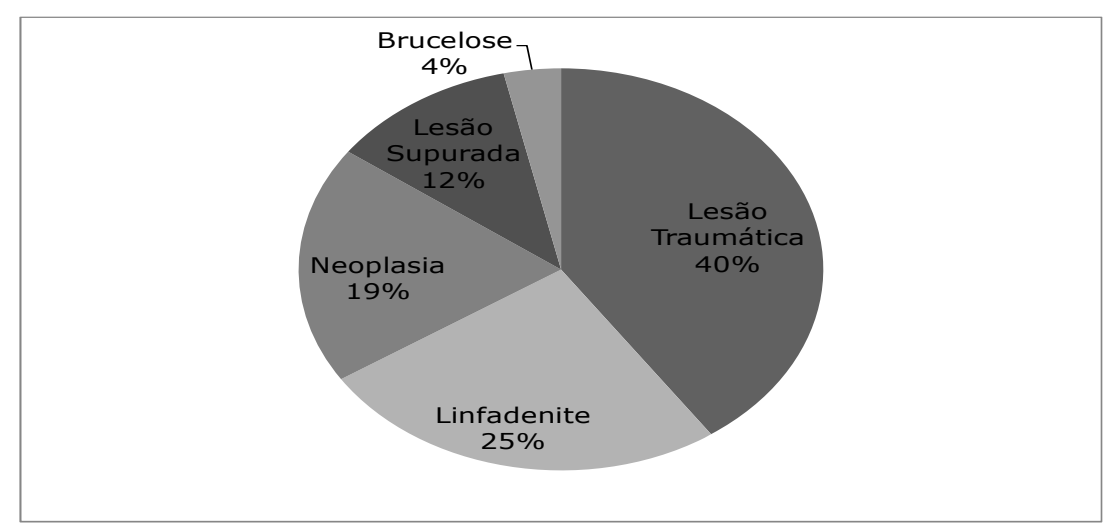

Gráfico 1. Porcentagem de cada uma das cinco maiores ocorrências postmortem verificadas no matadouro frigorífico exportador de Araguari-MG, no período de 2004 a 2008, em relação ao total dessas cinco ocorrências.

gráfico 2 representa a prevalência das principais ocorrências postmortem a cada ano em relação ao total de animais abatidos por ano.

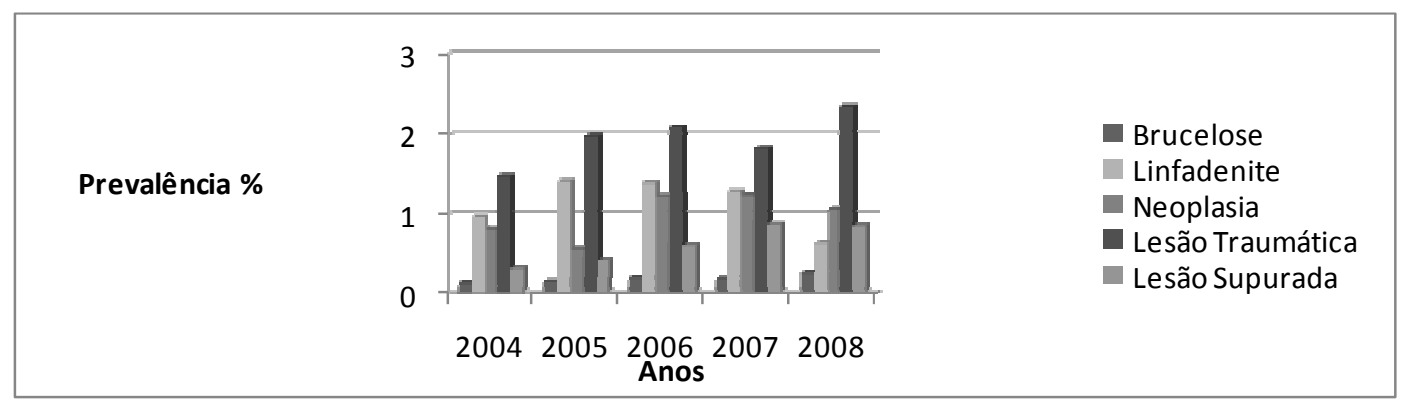

Gráfico 2. Prevalência (em porcentagem) das principais ocorrências postmortem no frigorífico exportador de Araguari - MG em relação ao total de animais abatidos em cada ano em relação ao total de animais abatidos por ano. 
FRANCO, J.F.L. et al. Lesões post-mortem de equinos abatidos em frigorífico exportador de Araguari - MG. PUBVET, Londrina, V. 5, N. 34, Ed. 181, Art. 1223, 2011.

Na Tabela 2 é apresentada a prevalência das principais ocorrências post- mortem para o mesmo frigorífico.

Tabela 2. Prevalência (em porcentagem) das principais ocorrências post-mortem em Frigorífico Exportador de Araguari - MG, no período de 2004 a 2008.

\begin{tabular}{ccccccc}
\hline Ocorrências & $\mathbf{2 0 0 4}$ & $\mathbf{2 0 0 5}$ & $\mathbf{2 0 0 6}$ & $\mathbf{2 0 0 7}$ & $\mathbf{2 0 0 8}$ & $\mathbf{2 0 0 4}$ a $\mathbf{2 0 0 8}$ \\
\hline Brucelose & 0,125 & 0,144 & 0,193 & 0,183 & 0,255 & 0,164 \\
Linfadenite & 0,969 & 1,407 & 1,39 & 1,28 & 0,65 & 1,193 \\
Neoplasia & 0,818 & 0,576 & 1,22 & 1,23 & 1,06 & 0,896 \\
Lesão Traumática & 1,47 & 1,99 & 2,10 & 1,84 & 2,35 & 1,886 \\
Lesão Supurada & 0,307 & 0,43 & 0,62 & 0,88 & 0,86 & 0,540 \\
\hline $\begin{array}{c}\text { TOTAL DE } \\
\text { OCORRÊNCIAS }\end{array}$ & 3,689 & 4,547 & 5,523 & 5,413 & 5,175 & 4,679 \\
\end{tabular}

Do total de 137.769 animais abatidos nos anos de 2004 a 2008 verificou-se que dentre as patologias analisadas a de maior ocorrência foi a lesão traumática com 2599 casos, com uma prevalência de 1,886\% (Tabela 1 e Tabela 2) e dentre as cinco alterações analisadas responde a $40 \%$ do total de ocorrências (Gráfico 1).

O resultado encontrado é justificado pelas condições inadequadas do transporte rodoviário que é responsável pela maioria dos traumas e contusões. O transporte rodoviário, embora mais viável economicamente, nem sempre é a melhor opção para o transporte de animais, as estradas não estão nas melhores condições e os motoristas nem sempre são capacitados para o transporte desse tipo de carga que exige certo cuidado. Segundo Roça (2002) o transporte rodoviário, que é o priorizado no Brasil, é o grande responsável 
FRANCO, J.F.L. et al. Lesões post-mortem de equinos abatidos em frigorífico exportador de Araguari - MG. PUBVET, Londrina, V. 5, N. 34, Ed. 181, Art. 1223, 2011.

por contusões, perda de peso, estresse e até a morte de animais. O número de lesões é diretamente proporcional ao tempo de transporte. Assim sendo, quanto maior a distância do confinamento ao frigorífico maior o número de injúrias nos animais bem como o número de animais machucados.

De acordo com Stull (2009) e Collins e colaboradores (2000) o espaço ocupado por animal é um dos aspectos que deveria ser especialmente considerado durante o transporte. O transporte de animais em alta densidade de carga muitas vezes utilizado para ser mais econômico acaba saindo mais caro pois resulta em aumento das contusões e estresse dos animais. O formato do caminhão, que é inadequado para o bem estar animal, também é responsável pela freqüência e quantidade de lesões.

Isso nos mostra que o maior problema não são as doenças causadas por agentes infecciosos e sim provavelmente no manejo dos animais especialmente no transporte que pode ser o maior responsável pelas lesões.

Moreira (2003), em estudos realizados na mesma localidade (Frigorífico Pomar S/A), nos anos de 1997 a 2001 relatou que as lesões traumáticas são as segundas maiores responsáveis pela condenação de carcaças, com prevalência de $0,31 \%$ de um total de 211620 animais abatidos, sendo superada apenas por neoplasia com $0,58 \%$ de prevalência. Segundo Neves (2007), em estudo realizado ainda no mesmo frigorífico, Pomar S/A, no período de 2003 a julho de 2006, as lesões traumáticas também estão em segundo lugar das principais patologias responsáveis pelas condenações de carcaça, com incidência de $1,20 \%$, e as neoplasias, principalmente o melanossarcoma, se encontra com a maior incidência acometendo 1,50 \% dos animais abatidos.

Ainda em relação aos dois estudos acima se pode dizer que de 1997 a 2008 a ocorrência de casos de lesão traumática vem tendo um aumento significativo ao longo dos anos. No período de 1997 a 2001 analisados por Moreira (2003), constatou-se prevalência de 0,31\%, já de 2003 a 2006 analisados por Neves (2007) prevalência subiu para $1,20 \%$ o que vem a 
FRANCO, J.F.L. et al. Lesões post-mortem de equinos abatidos em frigorífico exportador de Araguari - MG. PUBVET, Londrina, V. 5, N. 34, Ed. 181, Art. 1223, 2011.

corroborar com o estudo atual sendo que a prevalência no período de 2004 a 2008 aumentou para 1,88\%.

Adiferença encontrada em relação aos trabalhos citados pode estar na forma de contagem das ocorrências em relação ao número carcaças que pode ter sido diferente do trabalho em questão, já que no livro de registro são descritas apenas a soma dos quartos ou meia carcaças por dia, sendo impossível diferenciar se $2 / 4$ que tiveram mesmo destino são do mesmo animal ou de animais diferentes. Lembrando que a forma escolhida no trabalho em questão foi considerar cada 1/4 como uma ocorrência.

A patologia que aparece ocupando o segundo lugar, com um total de 1644 casos e prevalência de 1,193\%, é a linfadenite (Tabela 1 e Tabela 2). No gráfico 1 nota-se que ela representa 25\% das ocorrências em relação ao total das outras patologias analisadas. No gráfico 2 pode-se observar que dentre os anos analisados embora tenha obtido a segunda maior prevalência, no ano de 2008 a linfadenite com prevalência de 0,65\% é ultrapassada pela neoplasia que atinge prevalência de 1,06\%.

A linfadenite é uma inflamação dos nódulos linfáticos e pode ter causas diversas, a mais comum são os agentes infecciosos ou seus produtos (JONES et al, 2000).De acordo com Moraes e colaboradores (2009) a linfadenite, na sua forma purulenta, é relatada em casos como garrotilho, tuberculose e infecções micóticas, sendo que os nodos podem se apresentar atrofiados ou necrosados. Jones et al (2000) relatou que nas septicemias agudas como carbúnculo hemático a linfadenite hemorrágica pode ser observada.

De acordo com trabalho realizado por Moreira (2003), que analisou o período de 1997 a 2001, a linfadenite ocupou posição de terceiro lugar, dentre as principais patologias, com 411,50 casos e incidência de $0,19 \%$, de um total de 211620 animais abatidos. Neves (2007) em estudo no período de 2003 a 2006 também encontrou em seu trabalho a terceira posição para linfadenite mas tendo a prevalência desta um significativo aumento passando para 0,44\%, com 566 casos de um total de 128820 carcaças avaliadas. No atual trabalho analisando o período de 2004 a 2008 esse aumento foi maior ainda 
FRANCO, J.F.L. et al. Lesões post-mortem de equinos abatidos em frigorífico exportador de Araguari - MG. PUBVET, Londrina, V. 5, N. 34, Ed. 181, Art. 1223, 2011.

com a linfadenite conseguindo se estabelecer na segunda posição com 1644 casos e prevalência de 1,19\% de um total de 137769 animais abatidos.

A terceira posição dentre as patologias observadas no presente trabalho é ocupada pela neoplasia com 1235 casos e prevalência de 0,896\% (Tabela 1 e Tabela 2). No gráfico 1 as neoplasias apresentam $19 \%$ do total das patologias analisadas. Bonesi e colaboradores (1998) em seu trabalho relatou que das neoplasias que acometem os eqüinos os melanomas são os de maior ocorrência e dentre os animais domésticos os eqüinos são os animais mais afetados. Os animais com idade avançada, de pelagem branca ou tordilha, e acima de seis anos são os mais susceptíveis e a principal área afetada nessa espécie animal é a genital, períneo, ao redor do ânus, vulva e base da cauda, são denominados "melanoma perianal ou perineal".

Moreira (2003) e Neves (2007) encontraram em seus trabalhos as neoplasias como as patologias de maior incidência com prevalência de 0,58 \% e 1221,75 casos, e 1,5\% de prevalência e 1926 casos observados, respectivamente. Sendo assim pode-se dizer que no decorrer do período que vai de 1997 a 2006 houve um aumento na incidência de neoplasia, especificamente melanoma, passando de $0,58 \%$ para $1,5 \%$. Já no trabalho atual em relação aos anos de 2004 a 2008 a incidência diminuiu um pouco, tendo valor de 0,896\%.

$\mathrm{Na}$ quarta posição dentre as patologias analisadas se destaca a lesão supurada com um total de 744 casos e uma prevalência de 0,540\%, como apresentado nas tabelas 1 e 2 . No gráfico 1 representa $12 \%$ do total das patologias analisadas. Segundo Jones (2000) a lesão supurada ou inflamação purulenta pode ser uma reação com causas diversas como infecções e determinadas doenças e tem como característica a formação de grandes quantidades de pus, um exsudato purulento líquido de cor e consistência cremosas. As bactérias piogênicas são as causas das inflamações purulentas ou supurativas. Os principais integrantes desse grupo são os bacilos piogênicos. Uma das mais importantes doenças com inflamação purulenta característica é o mormo dos eqüinos. 
FRANCO, J.F.L. et al. Lesões post-mortem de equinos abatidos em frigorífico exportador de Araguari - MG. PUBVET, Londrina, V. 5, N. 34, Ed. 181, Art. 1223, 2011.

A lesão supurada em trabalho realizado por Moreira (2003) em relação aos anos de 1997 a 2001 obteve a prevalência de 0,09\% ocupando também o quarto lugar em relação as demais patologias analisadas. Neves (2007) em análise do período de 2003 a 2006 obteve também a posição de quarto lugar para lesão supurada mas incidência com um relevante aumento para 0,44\% . No presente trabalho a lesão supurada continuou a aumentar nos anos de 2004 a 2008 indo para 0,54\%.

Por fim, a patologia que ocupa o quinto lugar é a brucelose com prevalência de $0,164 \%$ e 226 casos (Tabela 1 e 2). No gráfico 1, a brucelose representa $4 \%$ do total das patologias analisadas neste trabalho.

A brucelose é uma doença de grande importância devido ao caráter zoonótico. Dentro das várias doenças transmissíveis entre animais e o homem, a brucelose é a mais amplamente disseminada pelo mundo, e tem grande impacto na economia já que animais infectados devem ser sacrificados (VASCONCELLOS et al., 1987). Para o frigorífico dependendo das condições da carcaça pode ir para o aproveitamento condicional o que não é vantagem pois o produto perde seu valor comercial que é maior quando in natura.

É importante ressaltar aqui que em trabalho realizado por Silva et al (2001) foi constatado que grande parte dos eqüinos diagnosticados positivamente para brucelose era criada junto aos bovinos, no mesmo pasto $(84,2 \%)$, sendo que nas propriedades analisadas $53,7 \%$ dos bovinos também foram diagnosticados com brucelose.

Em trabalhos realizados por Moreira (2003) no período de 1997 a 2001 e Neves (2007) no período de 2003 a 2006 mostram que a incidência de brucelose passou de $0,07 \%$ nos anos de 1997 a 2001 para $0,1 \%$ nos período de 2003 a 2006 e no trabalho atual, observado o período de 2004 a 2008, constatou-se que não houve aumento significativo com incidência de 0,16\%.

Essa baixa prevalência e reduzido número de casos se comparada às outras patologias não diminui a importância da brucelose. Também não implica que a doença vem passando por uma melhora no seu diagnóstico ou tenha conseguido um controle. Uma provável explicação é que devido aos 
FRANCO, J.F.L. et al. Lesões post-mortem de equinos abatidos em frigorífico exportador de Araguari - MG. PUBVET, Londrina, V. 5, N. 34, Ed. 181, Art. 1223, 2011.

sinais característicos da doença como a lesão na nuca ou cernelha os animais que apresentam esse sinal são descartados já na hora da compra e sequer chegam no frigorífico.

\section{Conclusão}

As principais ocorrências de eqüinos verificadas no frigorífico exportador de Araguari (SIF 1803) foram : lesão traumática, linfadenite, neoplasia, lesão supurada e brucelose.

A lesão traumática foi a ocorrência post-mortem de maior incidência verificada no matadouro frigorífico exportador de Araguari (Pomar SA) com valores de $1,886 \%$, sendo assim a maior causa de condenação de carcaças. A segunda maior ocorrência foi a linfadenite com prevalência de 1,193\%, seguida pela neoplasia com $0,896 \%$, em quarta posição a lesão supurada com 0,540\%, e por último a brucelose com 0,164\%.

\section{Referências}

ACHA, P. N.; SZYFRES, B. Zoonosis y enfermidades transmisibles comunes al hombre y a los animales. 3. ed. Washington: Organizacão Panamericana de Saúde, 2003. Disponível em: ( http://books.google.com.br). Acesso em: 04 dez. 2009

BONESI, L. G.; BRACARENSE, L.R.P.A.; MINELLI, L.; Melanoma em equídeos de pelagem branca - frequência, distribuição e lesões em carcaças: Investigação clínica,epidemiológica, laboratorial e terapêutica. Anais Brasileiros de Dermatologia, Rio de Janeiro, 73(6):533538, nov./dez.1998.

COLLINS, M.N.; et al. Effects of density on displacement, falls, injuries, and orientation during horse transportation. Applied Animal Behaviour Science, Texas,USA, v.67, p. 169-179, 2000.

JONES, T.C.; HUNT, R.D.; KING,N. W. Sistemas Hêmico e Linfático. In: Patologia

Veterinária.6. ed. Barueri: Manole, 2000. Cap. 22, p.1027 - 1061.

MORAES, C.M. et al.Adenite equina: sua etiologia, diagnóstico e controle. Ciência Rural, v.39, n.6, p.1944-1952, Santa Maria, $2009 . \quad$ Disponível em:(http://submission.scielo.br/index.php/cr/article/view/3955/917). Acesso em: 20 nov. 2009.

MOREIRA, M. D. et al. Principais causas de condenações de equinos em Matadouro Frigorifico Exportador situado no Triângulo Mineiro. Revista Higiene Alimentar. São Paulo, v. 17. p. 
125-126, 2003. Encarte: Trabalho apresentado no: CONGRESSO LATINO - AMERICANO DE HIGIENISTAS DE ALIMENTOS, 1., 2003, Belo Horizonte.

NEVES, E. A. Principais ocorrências sanitárias na inspeção Pós-mortem de equinos em matadouro frigorífico exportador da região do Triângulo Mineiro. 2007. 29 f. Monografia (Graduação em Medicina Veterinária)__ Faculdade de Medicina Veterinária, Universidade Federal de Uberlândia, Uberlândia, 2007.

ROÇA,R.O. Abate humanitário de bovinos. In: COFERÊNCIA VIRTUAL GLOBAL SOBRE PRODUÇÃO ORGÂNICA DE BOVINOS DE CORTE, 1., 2002.[S.I.;s.n.] Anais... Disponível em: (http://www.cpap.embrapa.br/agencia/congressovirtual/pdf/portugues/02pt03.pdf). Acesso em: 27 ago. 2009.

RODRIgUeS, P. T.; SILVA, T. J. P.; CARVALHO, E. C. Q.; FREITAS, M. Q.; PAULINO, F. O. Caracterização do processo de rigor mortis em músculos de eqüinos e maciez da carne. Ciência Rural, Santa Maria, v. 34, n. 4, jul/ago, 2004. Disponível em: (http://www.scielo.br/pdf/cr/v34n4/a40v34n4.pdf). Acesso em: 30 set. 2009.

SILVA,L. A. F.; ACYPRESTES, C. S.; EURIDES, D.; MACHADO, G. V.; DIAS FILHO, F. C.; FIORAVANTI, M. C. S.; RAMOS, L. S. Soroprevalência de brucelose em eqüinos com bursite cervical ou nucal. Arquivos de Ciência Veterinária e Zoologia da UNIPAR. v.4, n.1, p. 1923, jan./jun. 2001.

STULL, C. L. Responses of horses to trailer design, duration, and floor area during commercial transportation to slaughter. Journal of Animal Science, California, USA, v.77, ago. 1999. Disponível em:( http://jas.fass.org/). Acesso em: 27 ago. 2009.

VASCONCELLOS, S.A.; ITO, F. H.; CORTÊS, J. A. Bases para a prevenção da brucelose animal. Comum. Cient. FAc. Med. Vet. Vet. Zootec. USP, v.1, p.25-36, 1987. 